\title{
Comparative Studies of Different Control Strategies of a Dynamic Voltage Restorer Based on Matrix Converter
}

\author{
Amin Shabanpour and Ali Reza Seifi \\ School of Electrical \& Computer Engineering, University of Shiraz, Shiraz 7134851151, Iran \\ Correspondence should be addressed to Ali Reza Seifi, seifi@shirazu.ac.ir \\ Received 17 May 2012; Accepted 10 September 2012 \\ Academic Editor: Pavol Bauer
}

Copyright (C) 2012 A. Shabanpour and A. R. Seifi. This is an open access article distributed under the Creative Commons Attribution License, which permits unrestricted use, distribution, and reproduction in any medium, provided the original work is properly cited.

A dynamic voltage restorer (DVR) with no energy storage is studied. By using a matrix converter instead of the conventional $\mathrm{AC} / \mathrm{DC} / \mathrm{AC}$ converters, elimination of the DC-link capacitor is possible. The switching algorithm of matrix converter is the space vector modulation. There are different compensation algorithms to control the conventional DVR. These methods have been analyzed in this paper for the proposed matrix-converter-based DVR. A deep analysis through different diagrams would show the advantages or disadvantages of each compensation method. Equations for all methods are derived, and the characteristics of algorithms are compared with each other.

\section{Introduction}

Advanced industrials usually use electronic devices such as programmable logic controllers or power electronic drives in their devices. Power quality problems may affect the function of these devices. They could malfunction or trip through voltage disturbances. One of the most important power quality problems is voltage sag which is considered to be the most occurring issue in the power systems [1]. This phenomenon is specified as a sudden decrease in the voltage from $90 \%$ to $10 \%$ of rated voltage which lasts for half cycle to one minute. The main source of voltage sags are system faults, switching of heavy loads, or starting of large motors [2].

One of the best solutions to improve power quality is the dynamic voltage restorer (DVR). DVR is a kind of custom power devices that can inject active/reactive power to the grids. This can protect critical loads from disturbances such as sags or swells.

Four DVR topologies are compared in [3]. In this paper, the DVR with no energy storage devices and load-side connected shunt converter is selected. By using a matrix converter instead of the AC/DC/AC converters in that topology, the DC-link and its bulky capacitor would be eliminated.

Generally a matrix converter is a direct $\mathrm{AC} / \mathrm{AC}$ converter. A three-phase matrix converter has nine bidirectional switches that are able to connect any output phase of the system to any input phase at any time [4]. Some advantages of the matrix converter are bidirectional power flow, controllable sinusoidal output voltage, ability to control the input power factor, and a compact structure. However the complexity of its control is its main drawback [5].

Different DVR topologies based on matrix converters are presented before. A flywheel-supported DVR controlled by the matrix converter is proposed in [6]. Another topology is studied in [7] that the behavior of a DVR with matrix converter utilizing Alesina-Venturini modulation method is shown. In [8], a matrix converter-based DVR is analyzed which utilizes the space-vector modulation.

There are three compensation strategies for conventional DVR in literatures [9-11]. Comparisons between them are done in [12] for a general type of DVR but there is less study on compensation strategies for a matrix-converter-based DVR that is the aim of this paper. All compensation methods includes prefault, in-phase, and energy-optimized compensation algorithm are analyzed and compared in this paper for the matrix-converter-based DVR. Equations for each method are derived. Furthermore some parameters to characterize the behavior of each method for this special kind of DVR are defined. Finally, comparisons are done in various 


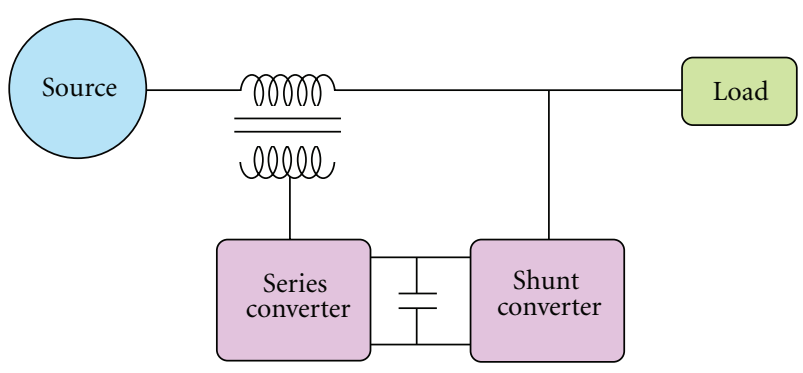

FIGURE 1: A DVR with no energy storage system and load-sideconnected converter.

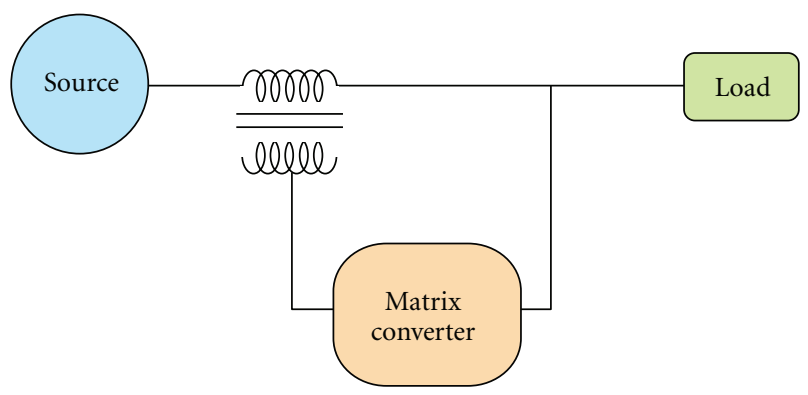

FIGURE 2: A DVR based on matrix converter.

aspects to show the characteristics of each compensating algorithm. Moreover, there are some studies on the DVR performance limitation in this topology.

In this paper, the structure of a DVR with matrix converter is introduced in Section 2. Different Compensation strategies in DVR are studied in Section 3. Comparison between the compensation methods with different aspects are done in Section 4, followed by the limitation of this DVR topology in Section 5. Finally, Section 6 concludes the discussion.

\section{DVR Topology}

DVR controls the load voltage by injecting an appropriate voltage during disturbances. It restores the load voltage to its rated value so that sensitive loads could operate in their normal conditions during disturbance. Injecting voltage may need active or reactive power and DVR should be able to provide that. Generally there are two types of DVR: the one with no energy storage system, and the one with energy storage system. Each type is divided to two categories: a supply-sideconnected converter, and a load-side-connected converter. All of these topologies are compared in [3]. Results show that the no energy storage DVR topology with load-sideconnected converter has better advantages over other topologies. This kind of structure for DVR is shown in Figure 1.

By replacing the two converters of this DVR with a matrix converter, the DC-link is removed. This topology is shown in Figure 2. The structure of a three phase to three-phase matrix converter is shown in Figure 3.

With appropriate switching algorithm, matrix converter is able to provide the required output voltage from its input

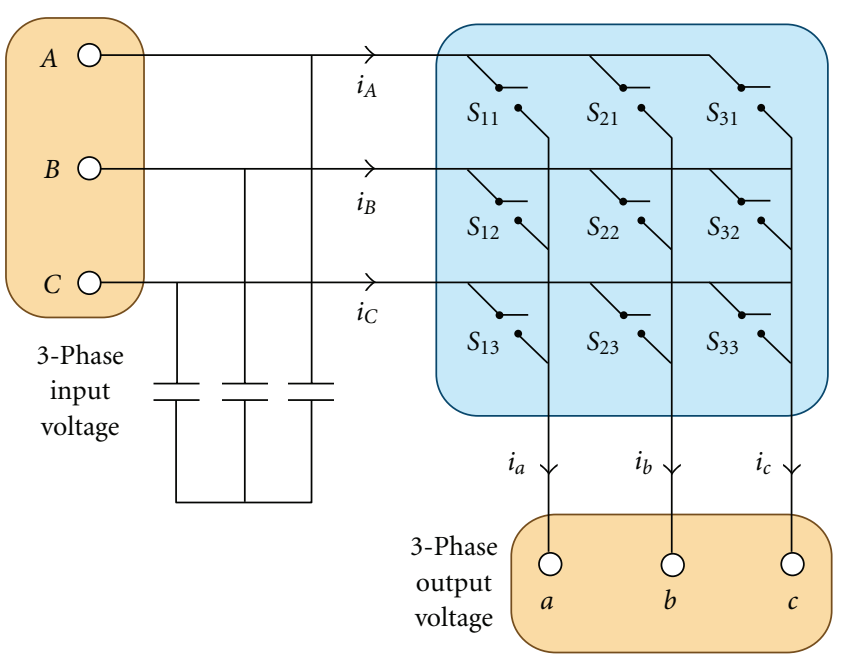

Figure 3: Matrix converter structure.

terminals. There are various modulation techniques to control matrix converter such as Alesina-Venturini modulation, Optimum Alesian-Venturini modulation, and Space Vector modulations (SVM). The last method is evaluated as the best one which is studied in [5].

\section{Compensation Strategies of DVR}

Load compensation could be done through active or reactive power injection by DVR. There are three compensation techniques based on using active, reactive, or both power by DVR. These methods are recognized as prefault compensation method, in-phase compensation method, and energyoptimized compensation method. These strategies are introduced in this section followed by derivation of their respective equations. Some simulations would show the characteristics of each method individually.

3.1. Prefault Compensation Method. This method is mainly used for loads that are sensitive to phase jump such as thyristor controlled drives. In other words, both magnitude and phase of the load voltage are compensated in this strategy such that the load voltage during disturbances is as same as the one before disturbances. Figure 4 shows this kind of compensation in per-unit plane.

In Figure $4, I_{\text {load }}^{\text {Prefault }}=1 \measuredangle 0$ is the load current before disturbance that is considered as the reference vector. The load is selected as a general type so the load voltage could be defined as $V_{\text {load }}^{\text {Prefault }}=1 \measuredangle \varphi$. The disturbance might change the source voltage magnitude from 1 to $k$ with $\delta$ degree phase jump. Therefore the source voltage after disturbance can be defined as $V_{s}^{\text {Postfault }}=k \measuredangle(\varphi+\delta)$. DVR should inject a voltage with appropriate magnitude and phase to compensate this disturbance. The DVR injected voltage is defined as $V_{\mathrm{DVR}}=$ $x \measuredangle \beta$. Also the load voltage and current after compensation are the same as their values before disturbance which means $V_{\text {load }}^{\text {Postfault }}=V_{\text {load }}^{\text {Prefault }}$ and $I_{\text {load }}^{\text {Postfault }}=I_{\text {load }}^{\text {Prefault }}$. Moreover the resultant phase jump between load voltage before and after disturbance, $\gamma$, is zero in this compensating method. By these 


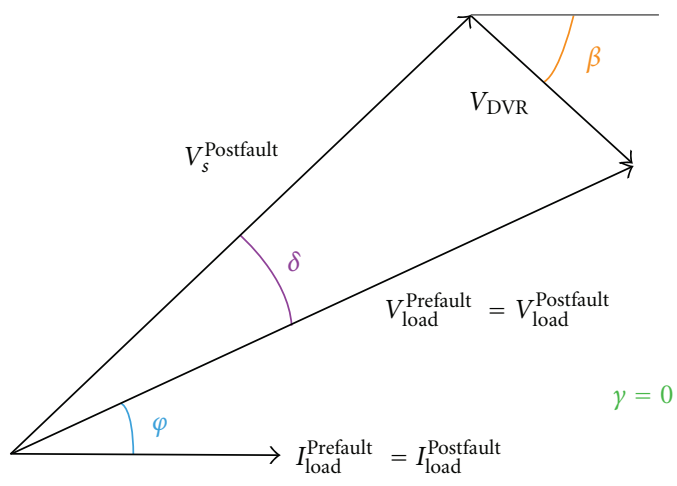

Figure 4: Prefault compensation strategy.

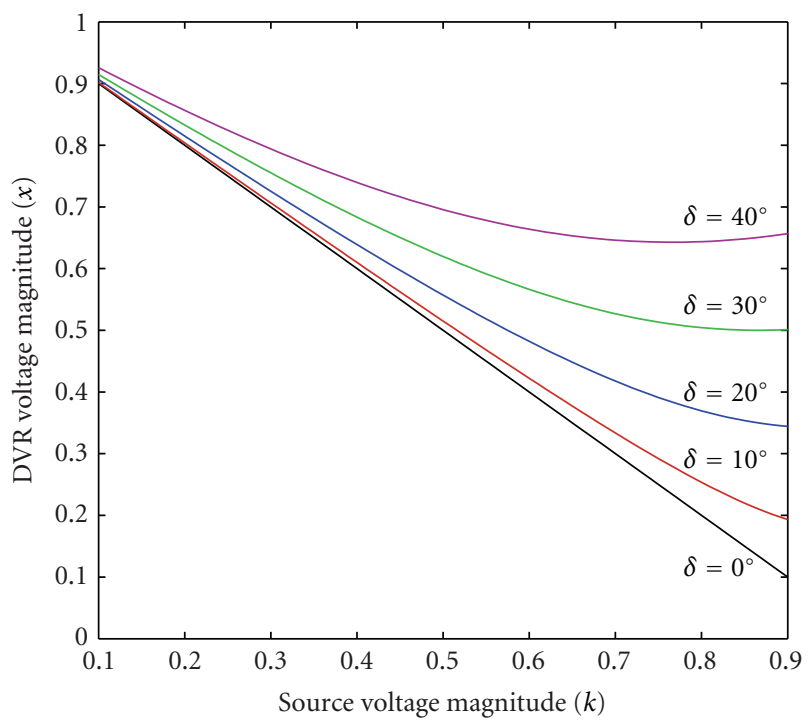

FIGURE 5: Prefault compensation strategy: the magnitude of the injected voltage versus the magnitude of the source voltage.

definitions, the DVR-injected voltage can be calculated as follows:

$$
\begin{aligned}
& V_{\mathrm{DVR}}= V_{\text {load }}^{\text {Postfault }}-V_{s}^{\text {Postfault }} \Longrightarrow \\
& V_{\mathrm{DVR}}= 1 \measuredangle \varphi-k \measuredangle(\varphi+\delta) \Longrightarrow \\
& V_{\mathrm{DVR}}= {[\cos (\varphi)-k \cos (\varphi+\delta)] } \\
&+j[\sin (\varphi)-k \sin (\varphi+\delta)] \Longrightarrow \\
& x=\sqrt{1+k^{2}-2 k \cos (\delta),} \\
& \beta=\tan ^{-1}\left(\frac{\sin (\varphi)-k \sin (\varphi+\delta)}{\cos (\varphi)-k \cos (\varphi+\delta)}\right) .
\end{aligned}
$$

Equation (2) shows that the magnitude of the injected voltage only depends on the degree of distortion in the input voltage waveform. Figure 5 shows this parameter versus the magnitude of the input voltage for different values of $\delta$.

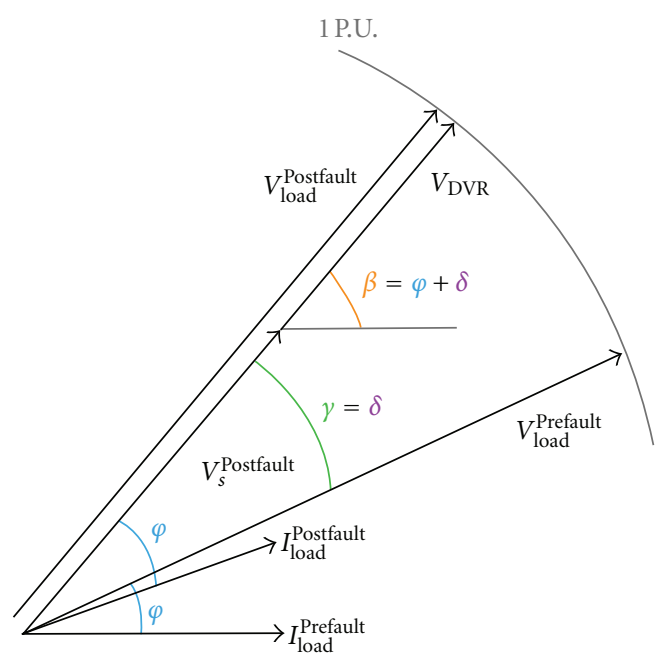

FIGURE 6: In-phase compensation strategy.

3.2. In-Phase Compensation Method. In this method, DVR only compensates the load voltage magnitude so the phase jump would be remained uncompensated. Figure 6 shows this control strategy. It is obvious that there is a phase difference between the load voltages before and after compensation. By using the same definitions in the previous section, the DVR-injected voltage is as follows:

$$
\begin{gathered}
V_{\mathrm{DVR}}=1 \measuredangle(\varphi+\delta)-k \measuredangle(\varphi+\delta)=(1-k) \measuredangle(\varphi+\delta) \Longrightarrow \\
x=1-k, \\
\beta=\varphi+\delta .
\end{gathered}
$$

Therefore, the load voltage after compensation can be written as $V_{\text {load }}^{\text {Postault }}=1 \measuredangle(\varphi+\delta)$, so that the load current would be $I_{\text {load }}^{\text {Postfult }}=1 \measuredangle \delta$. Moreover, there is a phase jump equal to $\gamma=\delta$ in the load voltage.

The magnitude of the injected voltage for any disturbance's phase jump and any load power factor is shown in Figure 7 that satisfies (5).

3.3. Energy-Optimized Compensation Method. It should be noticed that both previous strategies need a storage system to operate. However in energy-optimized method, the capacity of this storage system is minimized. Furthermore in shallow sags, the compensation could be done only with reactive power, and the amount of active power injection is zero. This strategy is based on injecting voltage in such a way that the injected voltage vector would be at almost $90^{\circ}$ to the resultant load current vector. This will minimize the injection of active power and even it may be zero. Figure 8 shows the basics of this strategy. 


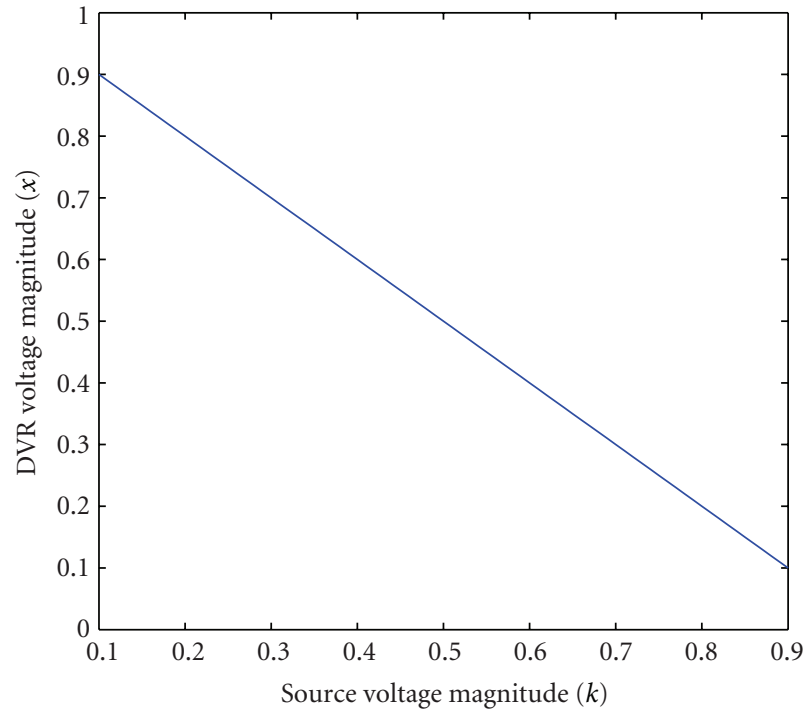

FIGURE 7: In-phase compensation strategy: the magnitude of the injected voltage versus the magnitude of the source voltage.

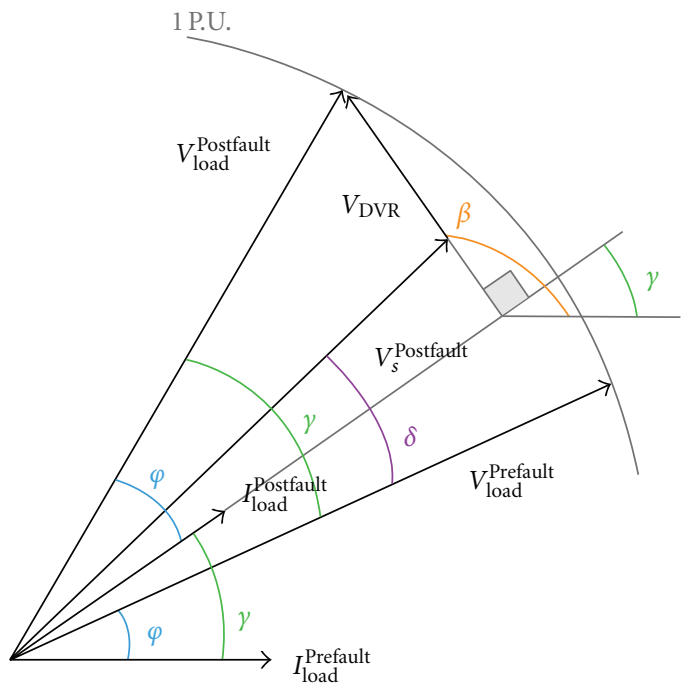

FIGURE 8: Energy-optimized compensation strategy.

With the similar definitions like previous sections for voltage and currents, the injected voltage can be calculated as follows:

$$
\begin{aligned}
& V_{\mathrm{DVR}}= V_{\text {load }}^{\text {Postfault }}-V_{s}^{\text {Postfault }} \Longrightarrow \\
& V_{\mathrm{DVR}}= 1 \measuredangle(\varphi+\gamma)-k \measuredangle(\varphi+\delta) \Longrightarrow \\
& V_{\mathrm{DVR}}= {[\cos (\varphi+\gamma)-k \cos (\varphi+\delta)] } \\
&+j[\sin (\varphi+\gamma)-k \sin (\varphi+\delta)] \Longrightarrow \\
& x=\sqrt{1+k^{2}-2 k \cos (\delta-\gamma),} \\
& \beta=\tan ^{-1}\left(\frac{\sin (\varphi+\gamma)-k \sin (\varphi+\delta)}{\cos (\varphi+\gamma)-k \cos (\varphi+\delta)}\right) .
\end{aligned}
$$

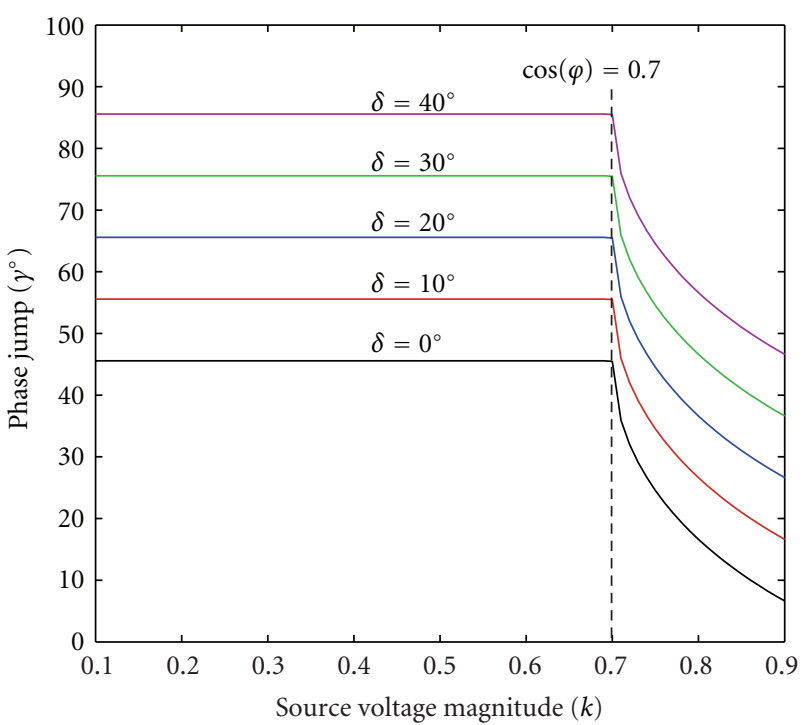

FIGURE 9: Energy-optimized compensation strategy: the phase jump of the load voltage versus the magnitude of the source voltage for $\mathrm{PF}=0.7$.

According to Figure 8 the injection voltage phase angle is $\beta=\pi / 2+\gamma$. By replacing this value in (9), the load phase jump can be calculated after some manipulations:

$$
\begin{gathered}
\tan ^{-1}\left(\frac{\sin (\varphi+\gamma)-k \sin (\varphi+\delta)}{\cos (\varphi+\gamma)-k \cos (\varphi+\delta)}\right)=\frac{\pi}{2}+\gamma \Longrightarrow \\
\frac{\sin (\varphi+\gamma)-k \sin (\varphi+\delta)}{\cos (\varphi+\gamma)-k \cos (\varphi+\delta)}=-\cot \gamma \Longrightarrow \\
\gamma=\varphi+\delta-\cos ^{-1}\left(\frac{1}{k} \cos (\varphi)\right) .
\end{gathered}
$$

To ensure that $(11)$ is feasible, $(1 / k) \cos (\varphi) \leq 1$ has to be established. So the source amplitude must be more than the load power factor or $k \geq \cos (\varphi)$. If this situation does not yield, $\gamma$ should be calculated through (12):

$$
\gamma=\varphi+\delta
$$

Figures 9 and 10 show the load phase jump and the injected voltage magnitude for different values of $\delta$. The load power factor is chosen as 0.7 .

In Figures 11 and 12, $\delta=30^{\circ}$ is constant and the load phase jump and the injected voltage magnitude is plotted for different load power factor. There are some notices in these figures. It should be noted that the injected voltage magnitude is independent of $\delta$. Moreover the break-points in these figures are relevant to the load power factor. In other words, the load can be compensated only through the injection of reactive power for $k \geq \cos (\varphi)$; otherwise there would be an active power injection too. 


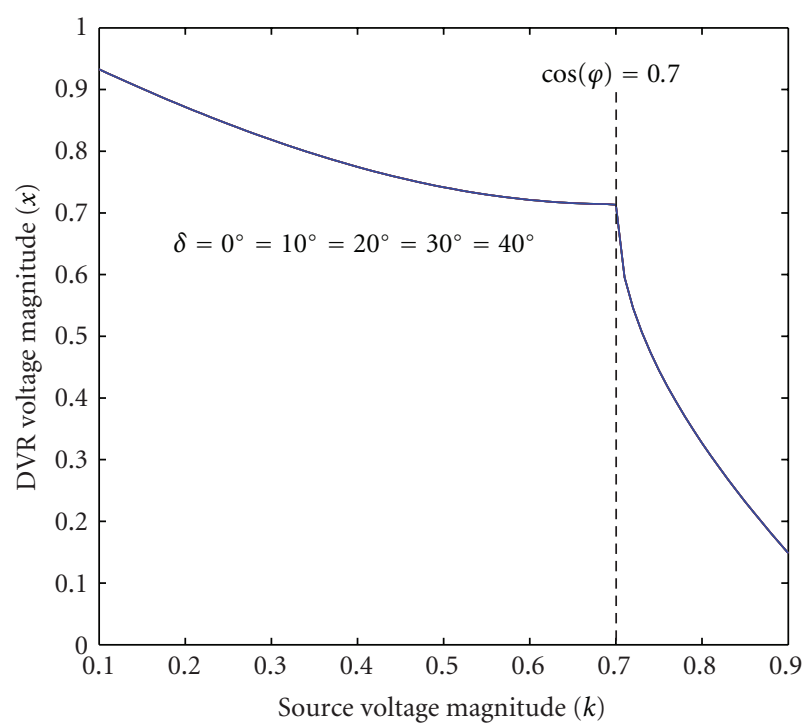

FIGURE 10: Energy-optimized compensation strategy: the magnitude of the injected voltage versus the magnitude of the source voltage for $\mathrm{PF}=0.7$.

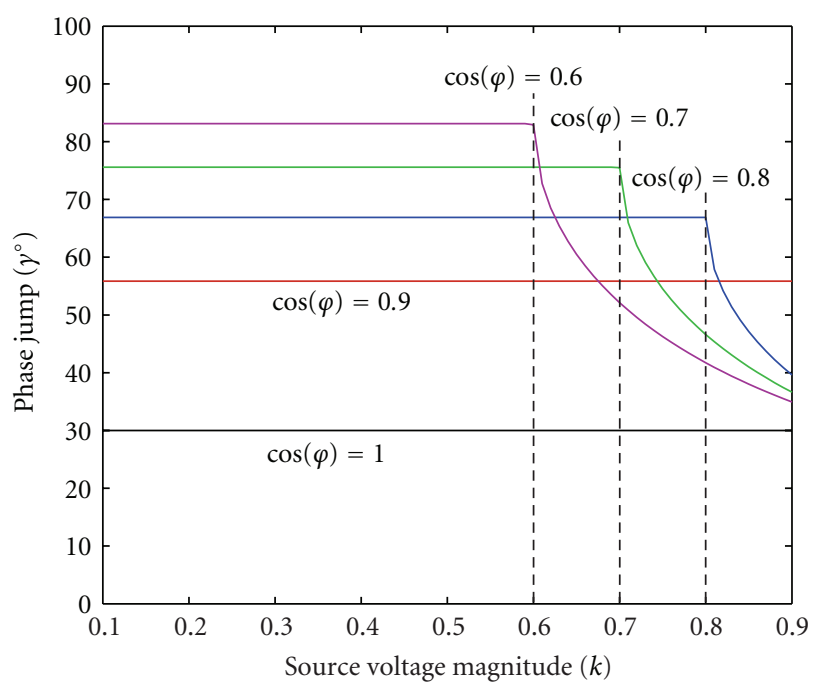

FIGURE 11: Energy-optimized compensation strategy: the phase jump of the load voltage versus the magnitude of the source voltage for $\delta=30^{\circ}$.

\section{Comparison between Compensation Strategies}

In this section, all compensation strategies are compared with each other. There are different criteria for comparison. Suppose that a disturbance with $\delta=45^{\circ}$ occurs and the load power factor is $\cos (\varphi)=0.6$.

4.1. Injection Voltage Magnitude. In Figure 13 the magnitude of the injected voltage versus the magnitude of the source voltage is shown for all compensation methods. It could be observed that the in-phase method has the least injection voltage magnitude. Furthermore for shallow disturbances,

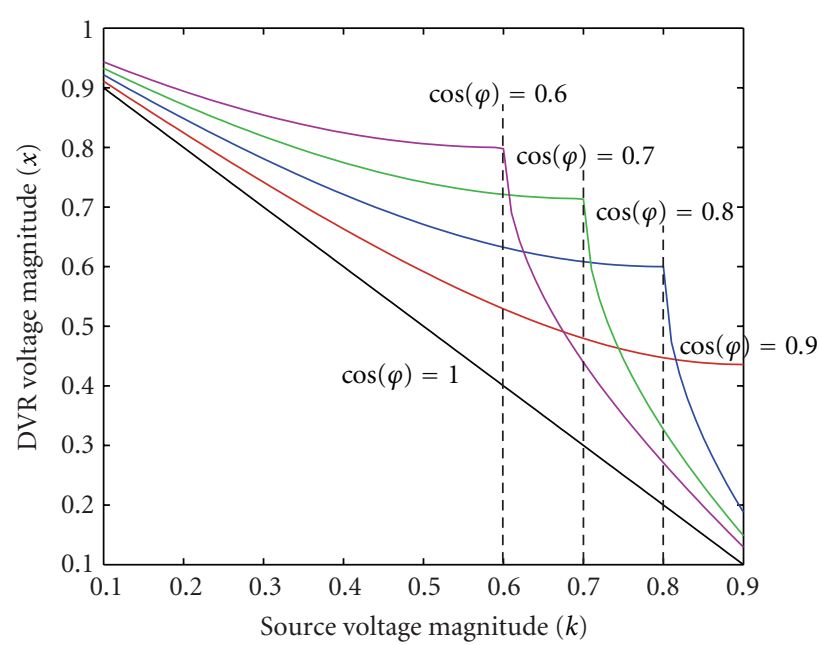

FIGURE 12: Energy-optimized compensation strategy: the magnitude of the injected voltage versus the magnitude of the source voltage for $\delta=30^{\circ}$.

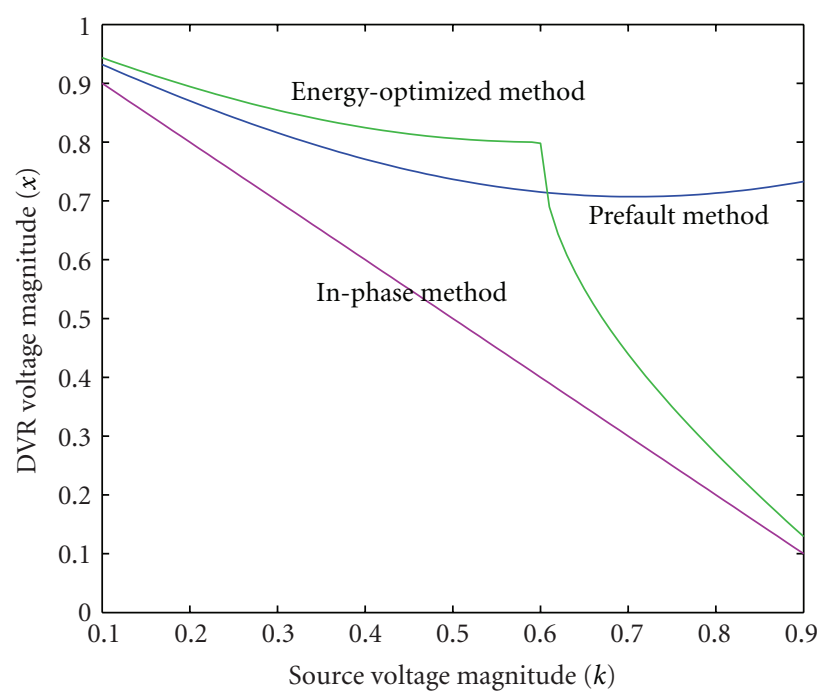

FIGURE 13: Comparison between different control strategies: the magnitude of the injected voltage versus the magnitude of the source voltage.

energy optimized method has less injection voltage magnitude than the prefault method. For large disturbances, the prefault compensation strategy has the most magnitude of the DVR injected voltage. This means that in this compensation method, DVR components should have a higher voltage rating compared with the other methods.

4.2. Load Voltage Phase Jump. Figure 14 shows the phase jump of the load voltage for the source voltage magnitude between 0.1 to 0.9 per unit. This figure shows that the energy optimized method has the most load phase jump angle followed by the in-phase method. This parameter can be a criterion of the load voltage distortion especially at the start and the end of the disturbance occurring time. The prefault method compensates the load voltage to its prefault value so it makes no phase jump in the load voltage. 


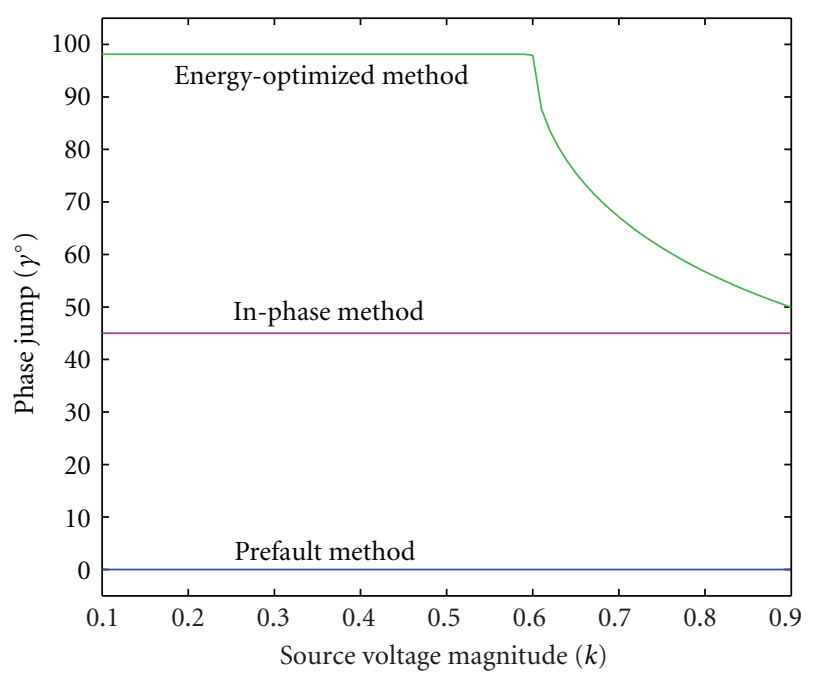

Figure 14: Comparison between different control strategies: the phase jump of the load voltage versus the magnitude of the source voltage.

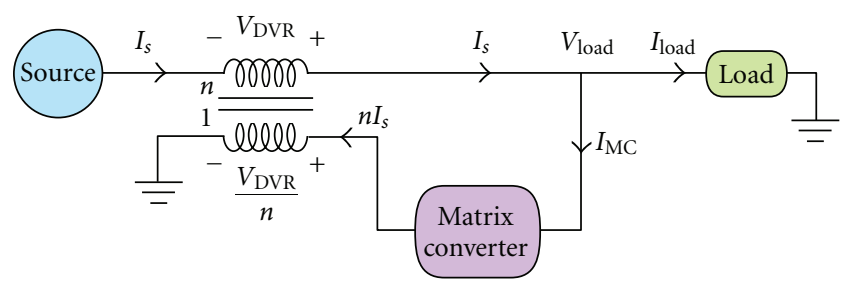

FIGURE 15: Schematics of a DVR based on matrix converter.

4.3. Source Current Magnitude. According to Figure 15, the matrix-converter-based DVR has no energy storage and the required power for compensation is taken from the grid itself. So the source current can be a comparative characteristic of different compensation techniques for this kind of DVR.

As it has been mentioned, matrix converter is able to control its input power factor. The matrix converter input voltage is the load voltage which is $V_{\text {load }}^{\text {Postfault }}=1 \measuredangle(\varphi+\gamma)$ after compensation. By considering a unity power factor for the input of matrix converter, the current of matrix converter would be $I_{\mathrm{MC}}^{\text {Postfault }}=y \measuredangle(\varphi+\gamma)$. Also the source current is defined as $I_{s}^{\text {Postfault }}=z \measuredangle(\zeta)$. Because there is no energy storage in the structure, the input and output active power of the matrix converter should be equal. Therefore

$$
\begin{gathered}
P_{\mathrm{MC}_{1}}^{\text {Postfult }}=P_{\mathrm{MC}_{2}}^{\text {Postfault }} \Longrightarrow \\
\operatorname{Re}\left\{\left[V_{\text {load }}^{\text {Postfault }}\right]\left[I_{\mathrm{MC}}^{\text {Postfault }}\right]^{*}\right\} \\
=\operatorname{Re}\left\{\left[\frac{1}{n} V_{\mathrm{DVR}}\right]\left[n I_{s}^{\text {Postfault }}\right]^{*}\right\} \Longrightarrow \\
\operatorname{Re}\left\{[1 \measuredangle(\varphi+\gamma)][y \measuredangle(\varphi+\gamma)]^{*}\right\} \\
=\operatorname{Re}\left\{[x \measuredangle \beta][z \measuredangle \zeta]^{*}\right\} \Longrightarrow \\
y=x z \cos (\zeta-\beta) .
\end{gathered}
$$

Now by using KCL we have

$$
\begin{aligned}
& I_{\text {load }}^{\text {Postfault }}= I_{s}^{\text {Postfault }}-I_{\mathrm{MC}}^{\text {Postfault }}=z \measuredangle \zeta-y \measuredangle(\varphi+\gamma) \Longrightarrow \\
& 1 \measuredangle \gamma=[z \cos (\zeta)-y \cos (\varphi+\gamma)]+j[z \sin (\zeta)-y \sin (\varphi+\gamma)] \Longrightarrow \\
& \sqrt{z^{2}+y^{2}-2 z y \cos (\zeta-\varphi-\gamma)}=1, \\
& \tan ^{-1}\left(\frac{z \sin (\zeta)-y \sin (\varphi+\gamma)}{z \cos (\zeta)-y \cos (\varphi+\gamma)}\right)=\gamma .
\end{aligned}
$$

After some manipulation, (17) yields to

$$
\sin (\zeta-\gamma)=\frac{y \sin (\varphi+\gamma)-y \tan (\gamma) \cos (\varphi+\gamma)}{z \sqrt{1+\tan ^{2}(\gamma)}} .
$$

By inserting (14) in to (18) we have

$$
\zeta=\tan ^{-1}\left(\frac{\sin (\gamma) \sqrt{1+\tan ^{2}(\gamma)}+x \cos (\beta) \mathcal{A}}{\cos (\gamma) \sqrt{1+\tan ^{2}(\gamma)}+x \sin (\beta) \mathcal{A}}\right),
$$

where $\mathcal{A}$ denotes $[\sin (\varphi+\gamma)-\tan (\gamma) \operatorname{csos}(\varphi+\gamma)]$ and by inserting (14) in to (16):

$$
z=\frac{1}{\sqrt{1+x^{2} \cos ^{2}(\zeta-\beta)-2 x \cos (\zeta-\beta) \cos (\zeta-\varphi-\gamma)}} .
$$

Equations (19) and (20) can be applied to all of the compensation strategies. It should be noted that for the prefault method $\gamma=0$, for the in-phase method $\gamma=\delta$, and for the energy optimized method $\gamma$ can be calculated by (11) or (12).

Figure 16 shows the magnitude of the input source current versus the magnitude of the source voltage for different control strategies. It shows that the energy optimized method and the prefault method has the most and the least magnitude of the input current, respectively. The higher value of the input current makes a more severe disturbance for the upstream loads because it makes more voltage drop. Moreover, the DVR components should have a higher current rating.

4.4. Matrix Converter Current Magnitude and Capacity. According to Figure 15, the postfault matrix converter current is $I_{\mathrm{MC}}^{\text {Postfault }}=y \measuredangle(\varphi+\gamma)$. The capacity of the matrix converter can be calculated as follows:

$$
\left|S_{\mathrm{MC}}\right|=\left|V_{\text {load }}^{\text {Postfault }}\right|\left|I_{\mathrm{MC}}^{\text {Postfault }}\right|=y .
$$

Figure 17 shows the magnitude of this current (or the matrix converter capacity) versus the magnitude of the source voltage. It can be seen that the energy optimized method needs least matrix converter rating to perform.

4.5. Voltage Transfer Ratio of Injection Transformer. According to Figure 15, the input and output voltage of matrix converter are related to each other:

$$
\left|\frac{V_{\text {DVR }}}{n}\right|=q\left|V_{s}^{\text {Postfault }}\right| \Longrightarrow n=\frac{x}{q k},
$$




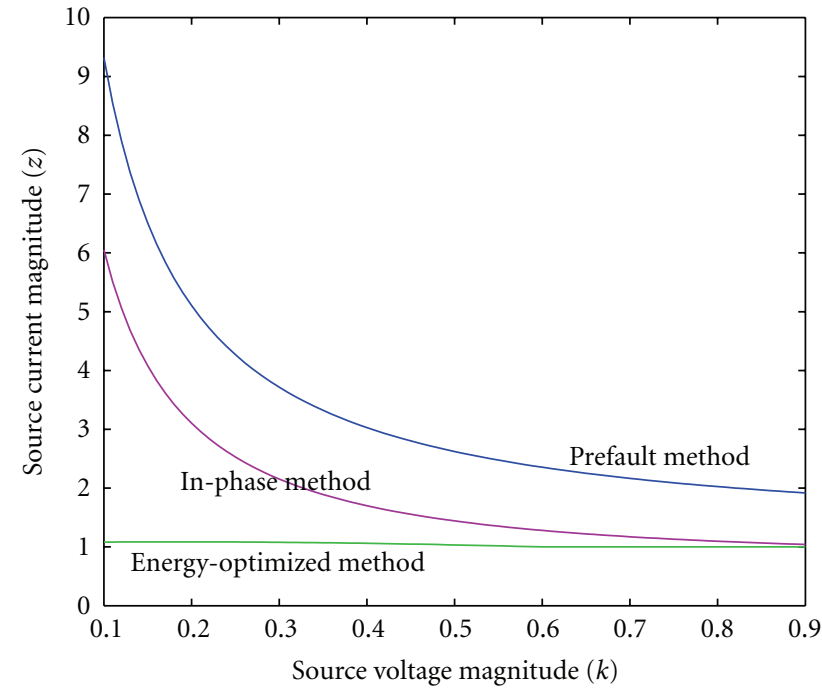

Figure 16: Comparison between different control strategies: the magnitude of the input source current versus the magnitude of the source voltage.

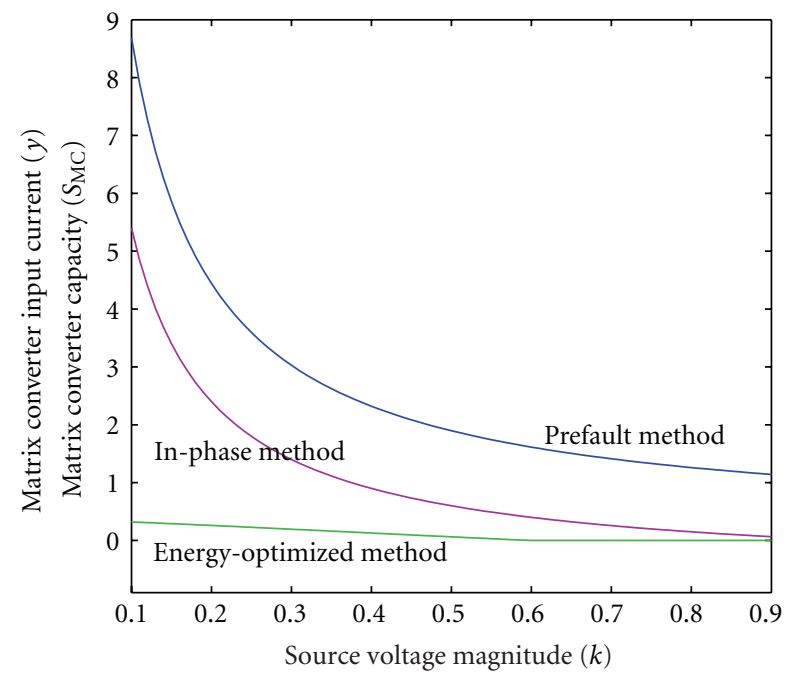

FIGURE 17: Comparison between different control strategies: Matrix converter input current (or capacity) versus the magnitude of the source voltage.

where $q$ is the matrix converter transfer ratio. The maximum value of $q$ is 0.866 [5]. Therefore the minimum value of the transformer voltage ratio can be calculated for every compensation algorithm. The result is plotted in Figure 18. For example the minimum value of $n$ to compensate a disturbance with $k=0.55$ are $1.52,0.94$, and 1.68 for prefault, in-phase, and energy-optimized method, respectively.

4.6. Injection Transformer Capacity. The injection transformer capacity can be calculated as follows:

$$
\left|S_{T}\right|=\left|V_{\text {DVR }}\right|\left|I_{s}^{\text {Postfault }}\right|=x z
$$

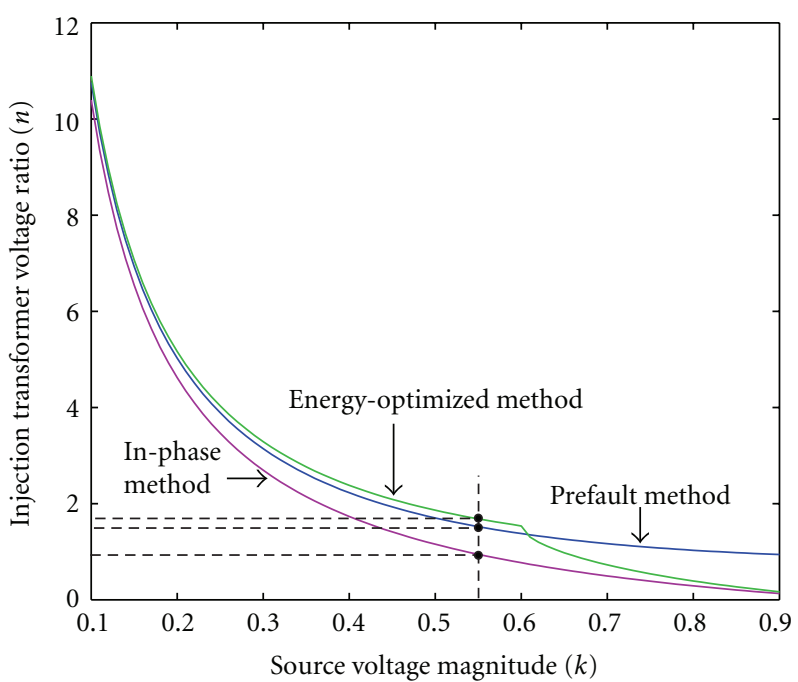

Figure 18: Comparison between different control strategies: the injection transformer voltage transfer ratio versus the magnitude of the source voltage.

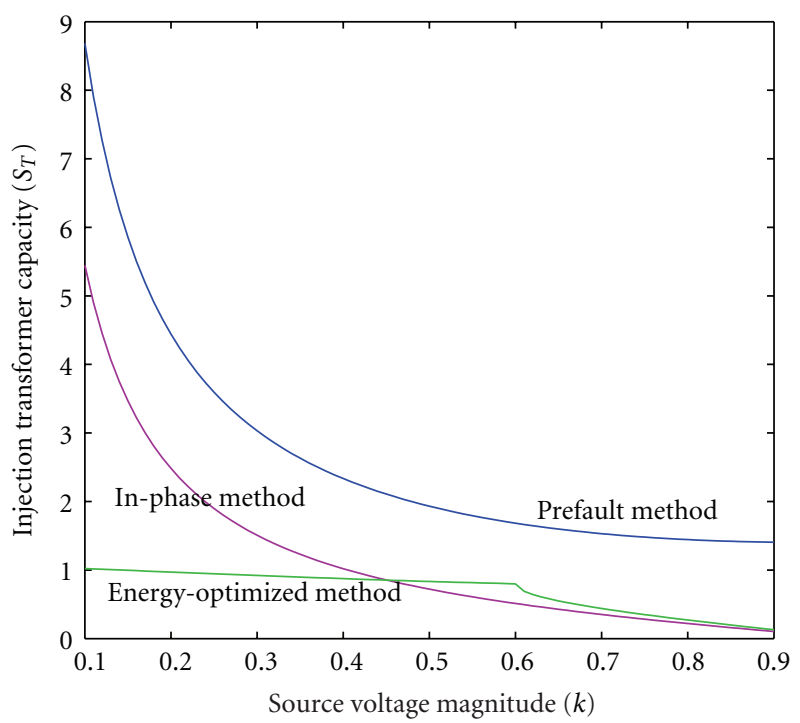

FIgure 19: Comparison between different control strategies: the injection transformer capacity versus the magnitude of the source voltage.

and Figure 19 shows this parameter characteristic for all compensation strategies.

\section{DVR Performance Limitation}

In the matrix-converter-based DVR, the compensation limit depends on the thevenin impedance of the network. For instance, in a deep Sag condition DVR consumes a large source current to compensate this disturbance because in this topology there is no energy storage device. This large current produces a large voltage drop on the network impedances. As it was mentioned before, the maximum voltage transfer ratio of a matrix converter is 0.866 , which is less than unity. 


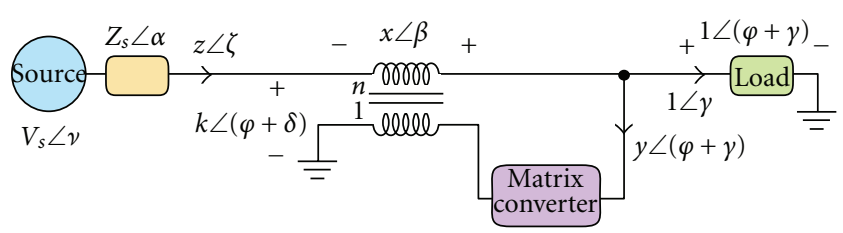

FIGURE 20: Effect of network thevenin impedance on DVR compensation limits.

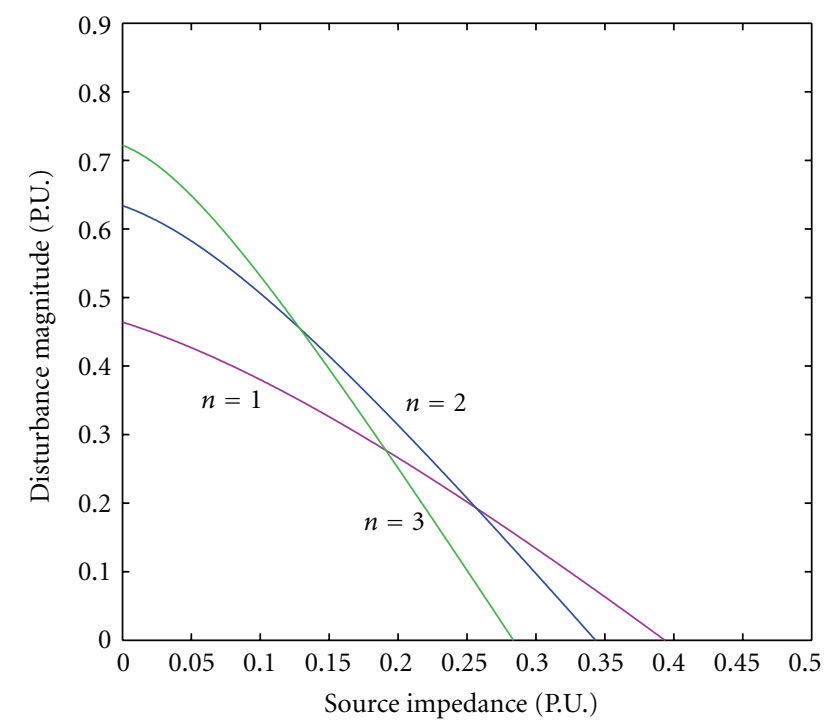

FIGURE 21: Maximum compensation capability versus the network thevenin impedance for different voltage ratio of injection transformer.

Therefore the maximum compensation capability of the DVR can be calculated. Equations (8) and (22) yield to:

$$
k=\frac{\cos (\delta-\gamma)-\sqrt{\cos ^{2}(\delta-\gamma)+n^{2} q^{2}-1}}{1-n^{2} q^{2}} .
$$

According to Figure 20, $V_{s}$ and $\delta$ can be calculated as follows:

$$
\begin{array}{r}
V_{s} \angle \nu-\left(Z_{s} \angle \alpha\right)(z \angle \zeta)=k \angle(\varphi+\delta) \Longrightarrow \\
\delta=-\varphi+\tan ^{-1}\left(\frac{V_{s} \sin (\nu)-Z_{s} z \sin (\alpha+\zeta)}{V_{s} \cos (\nu)-Z_{s} z \cos (\alpha+\zeta)}\right) \\
V_{s}=\sqrt{K^{2}+Z_{s}^{2} z^{2}+2 k Z_{s} z \cos (\varphi+\delta-\alpha-\zeta)} .
\end{array}
$$

Consider that $\gamma=0$ for the Prefault compensation method. Equations (9), (19), (20), (22), (24), (26), and (27) could be solved by numerical techniques. Figure 21 shows the maximum disturbance magnitude that can be compensated versus the amount of the network thevenin impedance for three transformer voltage ratio $\left(\cos (\varphi)=0.86, \alpha=85^{\circ}, v=\right.$ $30^{\circ}$ ). It shows that for small-grid impedances a larger transformer voltage ratio is needed to compensate voltage disturbances. However, this situation is different when the network impedance is large such as weak distribution networks.

\section{Conclusion}

In this paper, different compensation strategies to provide the injection voltage for a matrix-converter-based DVR are analyzed. Different comparison criteria are studied. Results show that if the load is sensitive to voltage phase jump, prefault method should be used. However, this method draws more current from the source which needs DVR components with higher current rating. If the load is insensitive to phase jump, either in-phase or energy optimized methods can be used to compensate it. The in-phase method has the least injection voltage magnitude that makes the components cheaper. Moreover for similar disturbance compensation, the in-phase strategy needs less transformer voltage ratio compared to other methods. The energy-optimized method needs the least input current magnitude to compensate disturbances. This will create less voltage drop for upstream loads and also the possibility to design a DVR with less current rating components. At the end the DVR limits are calculated for this topology. Results show that for a strong network a higher transfer ratio of the injection transformer brings the ability to compensate deeper sags. However for a weak network, that has larger short circuit impedance, a lower transfer ratio makes DVR compensating more severe disturbances.

\section{Acknowledgment}

It is a pleasure to thank those who made this work possible, especially Shiraz Electrical Distribution Company that supported this paper.

\section{References}

[1] D. D. Sabin, "An assessment of distribution system power quality," Tech. Rep. TR-106294-V2, Electric Power Research Institute, Palo Alto, Calif, USA, 1996.

[2] IEEE STD 1159-1995, "IEEE Recommended Practice for Monitoring Electric Power Quality".

[3] J. G. Nielsen and F. Blaabjerg, "A detailed comparison of system topologies for dynamic voltage restorers," IEEE Transactions on Industry Applications, vol. 41, no. 5, pp. 1272-1280, 2005.

[4] M. Venturini and A. Alesina, "Generalised transformer: a new bidirectional, sinusoidal waveform frequency converter with continuously adjustable input power factor," in Proceedinds of the IEEE Power Electronics Specialists Conference (PESC '80), pp. 242-252, Atlanta, Ga, USA, June 1980.

[5] D. Casadei, G. Serra, A. Tani, and L. Zarri, "Matrix converter modulation strategies: a new general approach based on spacevector representation of the switch state," IEEE Transactions on Industrial Electronics, vol. 49, no. 2, pp. 370-381, 2002.

[6] B. Wang and G. Venkataramanan, "Dynamic voltage restorer utilizing a matrix converter and flywheel energy storage," in Proceedings of the IEEE Industry Applications Conference 42nd IAS Annual Meeting, pp. 208-215, September 2007.

[7] E. Babaei and M. F. Kangarlu, "A new topology for dynamic voltage restorers without dc link," in Proceedinds of the IEEE Symposium on Industrial Electronics \& Applications (ISIEA '09), pp. 1016-1021, October 2009.

[8] J. M. Lozano, J. M. Ramirez, and R. E. Correa, "A novel dynamic voltage restorer based on matrix converters," in Proceedings 
of the IEEE Proceedings Modern Electric Power Systems (MEPS '10), Wroclaw, Poland, 2010, paper 15.2.

[9] M. Jazayeri and H. Abdollahzadeh, "A novel DVR control system design for compensating all types of voltage sags based on pre-fault method," European Journal of Scientific Research, vol. 33, no. 1, pp. 70-85, 2009.

[10] S. Zhe, G. ChunLin, X. YongHai, X. XiangNing, L. Yingying, and T. Shun, "A new analysis method for compensation strategy of DVR and minimum energy control," in Proceedings of the 5th IEEE Conference on Industrial Electronics and Applications (ICIEA '10), pp. 1321-1325, June 2010.

[11] J. G. Nielsen, F. Blaabjerg, and N. Mohan, "Control strategies for dynamic voltage restorer compensating voltage sags with phase jump," in Proceedings of the16th Annual IEEE Applied Power Electronics Conference and Exposition (APEC '01), vol. 2, pp. 1267-1273, March 2001.

[12] R. Strzelecki and G. Benysek, "Control strategies and comparison of the dynamic voltage restorer," in Proceedings of the 6th International Conference on Power Quality and Supply Reliability, pp. 79-82, August 2008. 

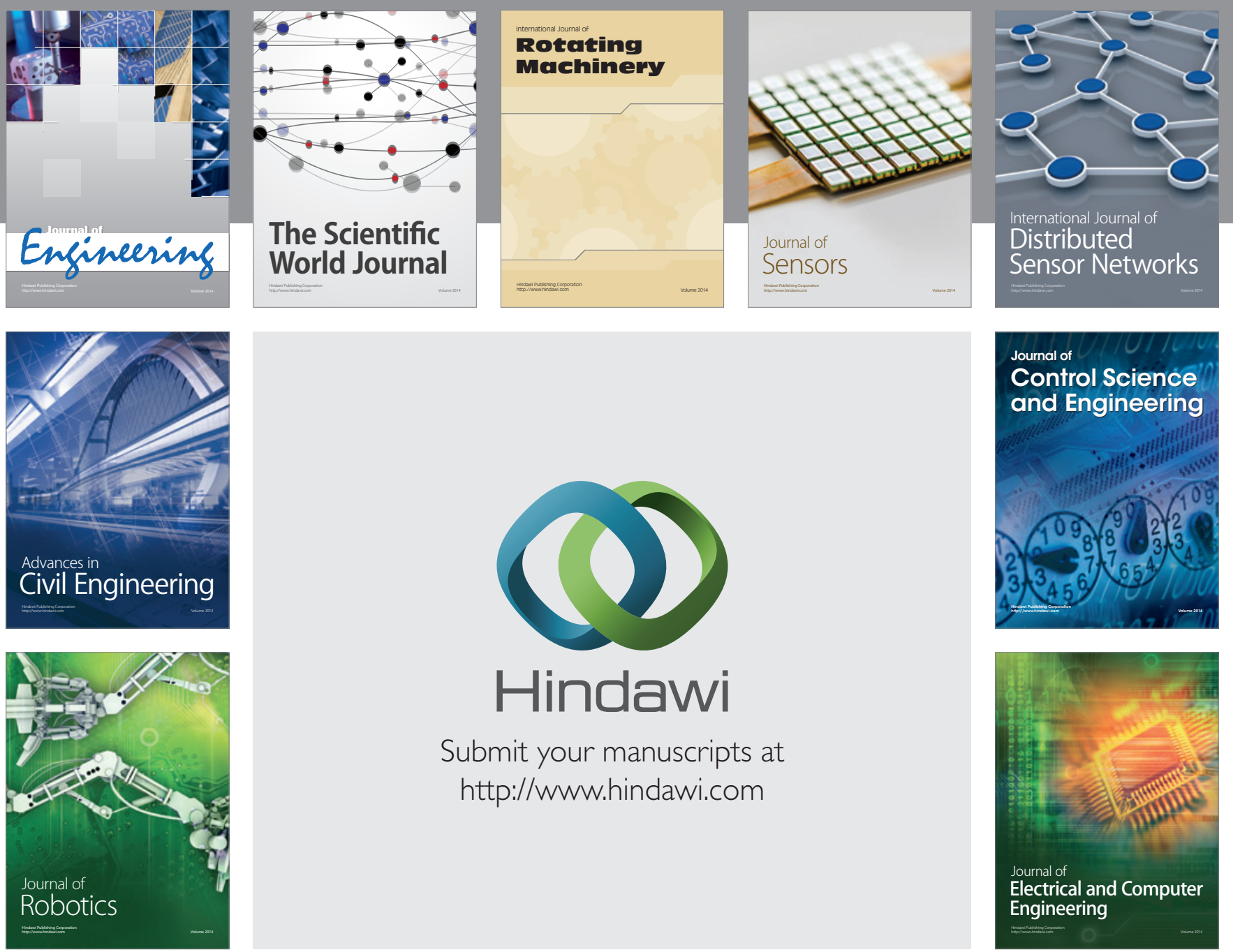

Submit your manuscripts at

http://www.hindawi.com
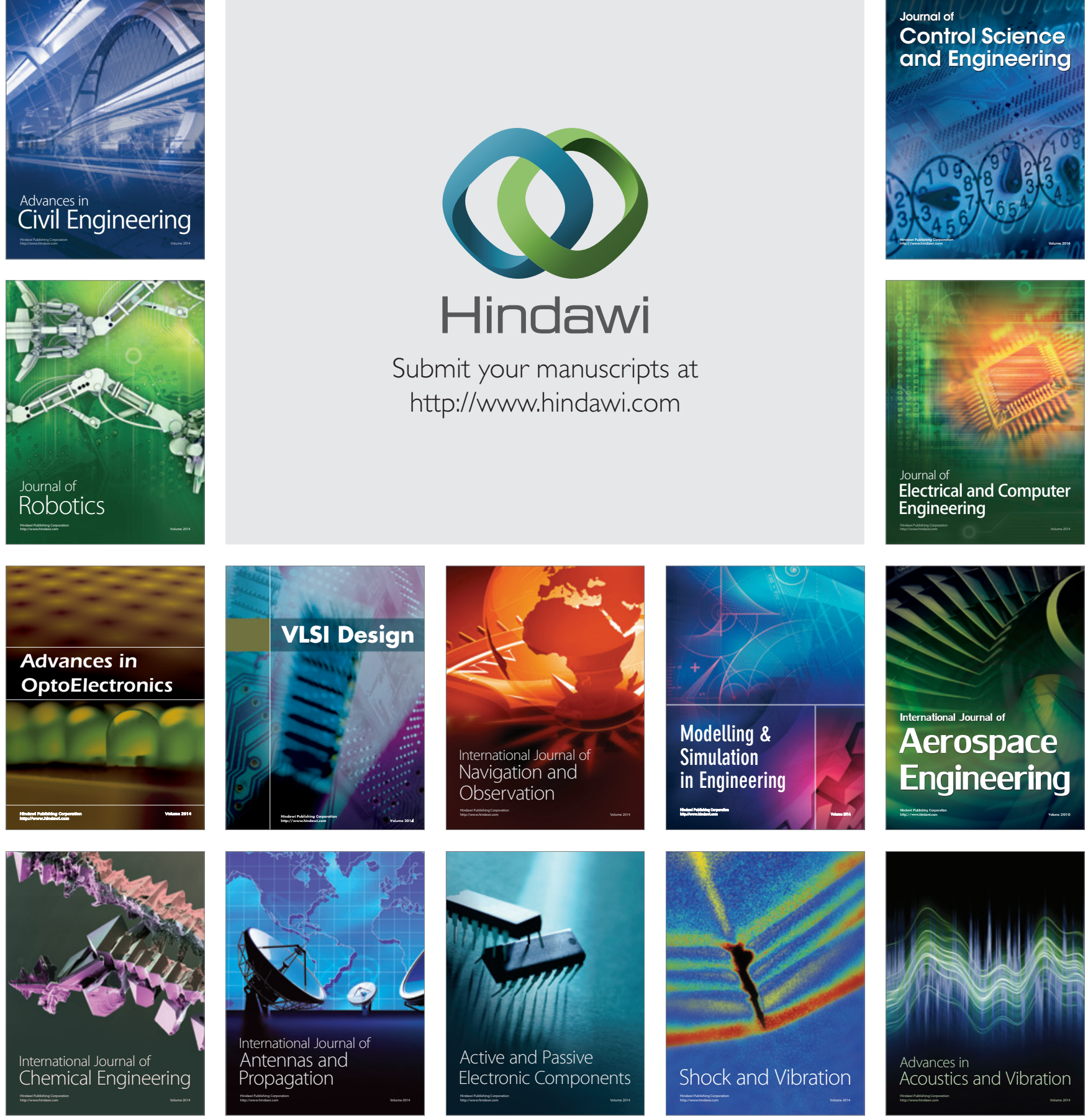